\title{
Secondary human impacts on the forest understory of Ulleung Island, South Korea, a temperate island
}

\author{
Desiree Andersen ${ }^{1,2}$ (B)
}

\begin{abstract}
Oceanic islands are biologically important for their unique assemblages of species and high levels of endemism and are sensitive to environmental change because of their isolation and small species source pools. Habitat destruction caused by human landscape development is generally accepted as the main cause of extinction on islands, with exotic species invasion a secondary cause of extinction, especially on tropical islands. However, secondary impacts of human development (e.g., general degradation through resource use and exotic species introduction) are understudied on temperate islands. To determine secondary impacts of human development on the understory vegetation community, 90 field sites on Ulleung Island, South Korea, were sampled during the summer of 2016. Understory vegetation was chosen as it is a proxy for ecosystem health. Diversity and percent cover of introduced, native, and endemic species were tested against proximity to developed areas and trail usage using a model selection approach. Diversity was also tested against percent cover of three naturalized species commonly found in survey plots. The main finding was that distance to development, distance to town, and trail usage have limited negative impacts on the understory vegetation community within best-supported models predicting native and introduced cover and diversity. However, endemic species cover was significantly lower on high usage trails. While there are no apparent locally invasive plant species on the island at the time of this study, percent cover of Robinia pseudoacacia, a naturalized tree species, negatively correlated with plot diversity. These findings indicate that forests on Ulleung Island are not experiencing a noticeable invasion of understory vegetation, and conservation efforts can be best spent preventing future invasions.
\end{abstract}

Keywords: Biodiversity, Introduced species, Oceanic islands, Plant ecology, Temperate forests, Ulleung Island

\section{Background}

Human colonization and landscape development of oceanic islands have caused a loss of global biodiversity through habitat loss and competition with and predation by exotic introduced species (Heywood, 1979; Sax and Gaines, 2008; Vitousek, 1988; Vitousek et al. 1995). This loss of biodiversity is due to the extinction of endemic species, or species that are found across a limited geographic range. Because of the isolation inherent to islands, these species have small or nonexistent source pools and limited ability to migrate when their habitat becomes inhospitable. The fragility of island ecosystems

Correspondence: desireeka93@hotmail.com

${ }^{1}$ Interdisciplinary Program of EcoCreative, Ewha Woman's University, 52

Ewhayeodae-gil, Seoul 03760, Republic of Korea

${ }^{2}$ The Evergreen State College, Olympia, Washington 98505, USA and their species is important to research in order to understand the underlying processes of human-caused extinction and to better inform management decisions to preserve at-risk species.

Islands have long been recognized for their importance in ecological and evolutionary research. By studying islands, scientists and naturalists have made strides in understanding processes that shape ecosystems and create new species. As important as they are for studying and understanding ecological functions, islands are equally so as biological and genetic resources. Isolation and subsequent evolution of island species often lead to high percentages of endemic species, especially on islands that are highly isolated (Adsersen, 1995; Eliasson, 1995). Because of this isolation and lack of regional species source pools, island ecosystems can be more

(C) The Author(s). 2019 Open Access This article is distributed under the terms of the Creative Commons Attribution 4.0 International License (http://creativecommons.org/licenses/by/4.0/), which permits unrestricted use, distribution, and 
susceptible to environmental change and stochastic events which can cause species extinction and affect ecosystem equilibrium. This is becoming especially relevant with increased human influence on natural ecosystems, in terms of both direct and indirect influence. Direct influence may include habitat loss through human development, while indirect influence includes gradual ecosystem change or stochastic events brought on by human-induced factors such as exotic species introduction, increased edge effects, or climate change.

A broader understanding of human impacts on temperate island ecosystems is important because they are biologically diverse ecosystems that have restricted gene and species flow and are therefore more susceptible to endemic species extinctions and ecosystem change than mainland sites. Nevertheless, the effects of human influence on these sensitive ecosystems are understudied. Accordingly, this study will contribute to the knowledge of other ecologically diverse temperate island ecosystems by looking at biodiversity and composition of the understory plant community on the study island.

\section{Study area: Ulleung Island}

Ulleung Island, Gyeongsanbukdo, South Korea, is a small, isolated volcanic island located $130 \mathrm{~km}$ east of mainland South Korea in the sea of Japan (locally known as the East Sea; Fig. 1). Ulleung Island, also known as Ulleungdo, is approximately $73 \mathrm{~km}^{2}$ in area (Yoon et al. 2013) and hosts up to 685 plant taxa, including 41 taxa of rare plants, and 30 taxa of endemic plants (Yoon et al. 2013). The high species richness (and presumed biodiversity) of the island makes it an excellent candidate for ecological study. In particular, studying human proximity impacts on biodiversity on Ulleung Island can illuminate the influence of anthropogenic activity on ecologically diverse temperate island ecosystems. Currently, there are up to 89 taxa of naturalized, or introduced, plants on the island (Jung et al. 2013), but their effect on the ecosystem has not been studied, so it is unknown whether any of the naturalized taxa could be considered invasive. Interestingly, there is one species that is controlled by cutting on Ulleung Island, Japanese knotweed (Fallopia sachalinensis), which is native (Andersen, 2015). However, the control for the species, predominantly in altered streams near towns, appears to be more for anthropogenic gain than for preserving biodiversity and ecosystem function.

Yang et al. (2015) provide a study of the presence and distribution of naturalized plant species on Ulleung Island. This article indicates problem areas of naturalized species (introduced species that have become integrated into the native plant community) around towns, which supports the hypothesis that human influence is a driver of the success of these species. However, this acts more as a species inventory rather than a controlled study of biodiversity, and therefore a more in-depth study is needed to understand the community dynamics of naturalized, native, and endemic species.

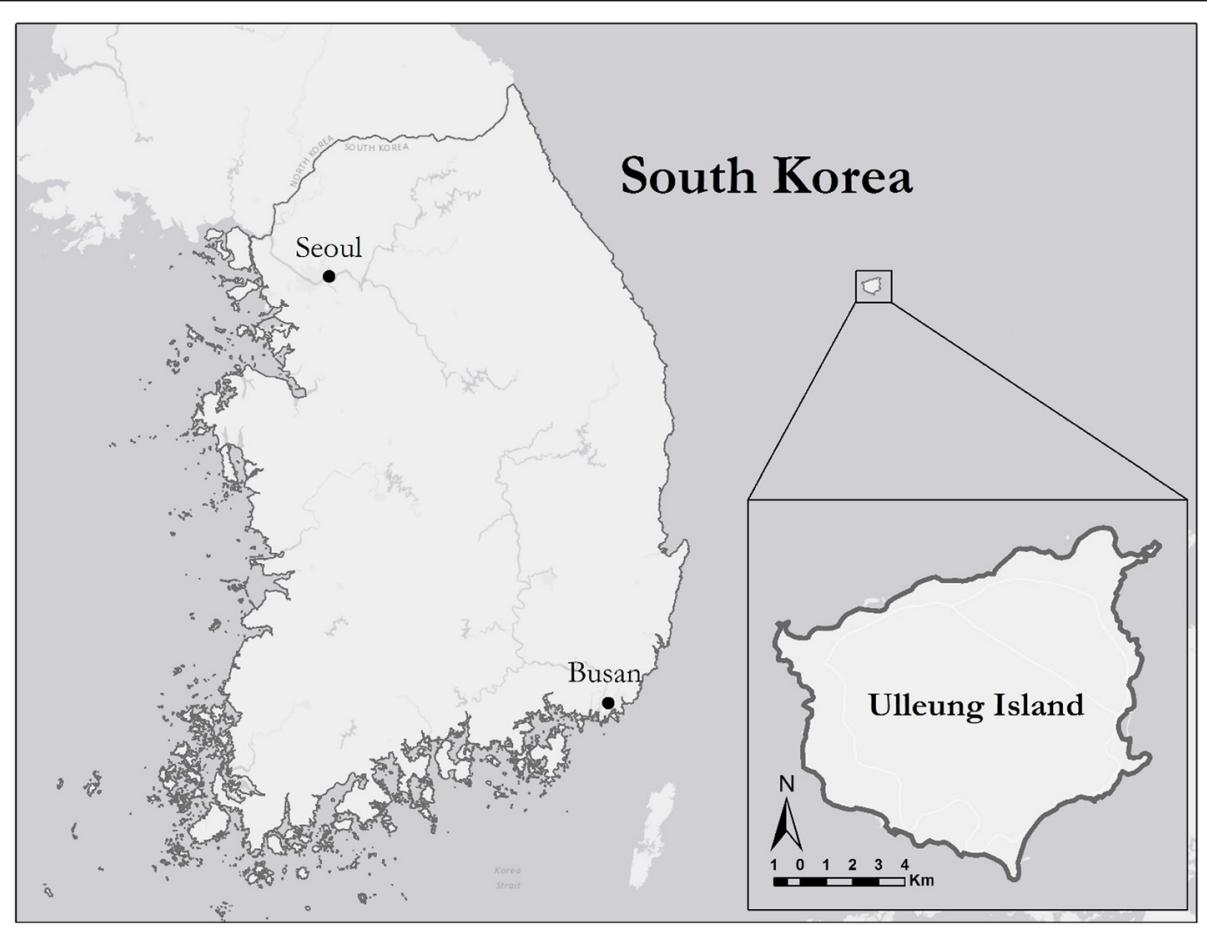

Fig. 1 Location of Ulleung Island in relation to South Korea 
Currently, there appears to be no or minimal vascular plant species loss on Ulleung Island (Nakai, 1919; Oh, 1978; Yang et al. 2015; Yoon et al. 2013). There are 9 taxa (or unique species/subspecies/forms) of critically endangered plants, 6 taxa of endangered plants, and 12 taxa of vulnerable plants designated by the IUCN on Ulleung Island (Yang et al. 2015). However, it is unclear whether these taxa are designated because their populations were limited prior to human colonization and development or if their populations have been reduced primarily due to human activity. Further, the role of secondary impacts of development (competition with introduced species, habitat degradation, edge effects, etc.) on these taxa is unknown for Ulleung Island.

\section{Methods}

\section{Site selection}

Survey sites were randomly preselected in QGIS 2.6 Brighton software along established trail tracks. Additional sites were added in the field where preselected sites were inaccessible due to the terrain. These additional sites were added at 100 and $200 \mathrm{~m}$ away from existing sites. Sites were selected to represent three forest canopy types (evergreen, mixed, deciduous) along with all major and minor trails on the island-where the terrain allowed-at varying distances from developed areas. Site selection resulted in a total of 90 sites (Fig. 2).

\section{Field data collection}

Vegetation was sampled across Ulleung Island during June and July of 2016. A total of 90 sites were surveyed with three sample quadrats at each site for a total of 270 $1 \mathrm{~m}^{2}$ plots. A quadrat was defined as a $1 \mathrm{~m}$ by $1 \mathrm{~m}^{2}$ plot. At each site, a GPS point was first taken with a Garmin eTrex 10 GPS using waypoint averaging for accuracy. Habitat metrics were recorded at each site and then vegetation data was collected at each of the three quadrat plots per site. Habitat metrics included trail name, elevation (taken from Garmin eTrex 10 GPS), canopy type (evergreen, mixed, deciduous), canopy percent cover, canopy composition (species), and aspect.

Quadrat plots were laid along the trail at the collected GPS point and at $5 \mathrm{~m}$ away on either side of the collected point. Within each plot, all vascular plant species below eye level were recorded and then estimated for percent cover. Percent cover was used as a proxy for abundance as it more accurately represents the prevalence and influence of each species on the landscape. These species were later coded as introduced or native-and endemic if applicable-according to Jung et al. (2013).

\section{Analysis}

The main variables analyzed were the composition of the understory plant community and the proximity (distance) to human influence (towns, presence of human development), as well as trail usage. Proximity to

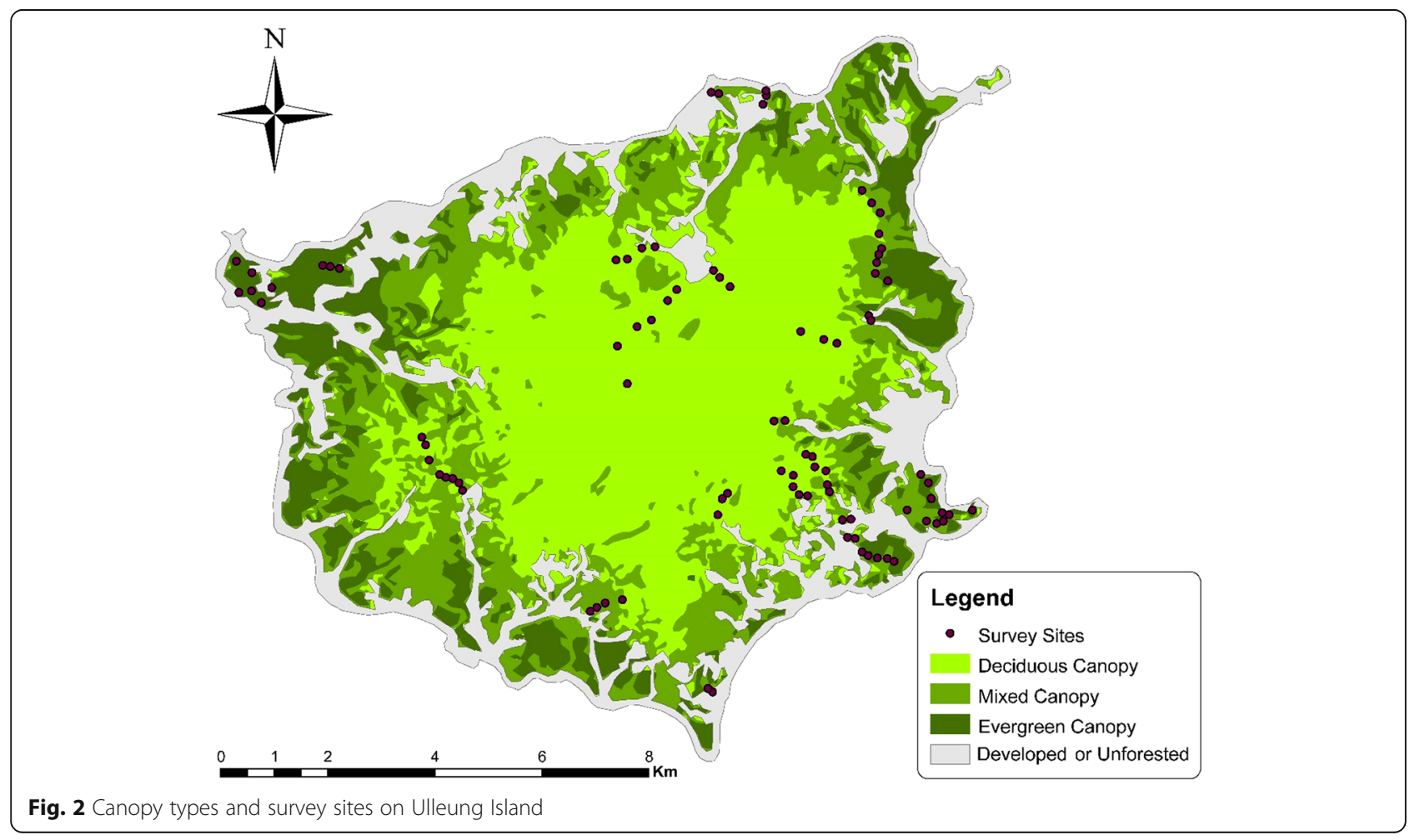


human influence was measured by two metrics: distance to development, and distance to the nearest town. Distance to development was defined as the Euclidean distance to the nearest modified surface identified from Landsat 7 maps, while the distance to town was defined as the Euclidean distance to the nearest town center. Trail usage was graded on traffic observed during surveys, where usage was defined as high when numerous individuals were encountered, medium when few individuals were encountered, and low when no other people were encountered during surveys.

Possible confounding site factors included canopy type and cover, elevation, aspect, and distance to the coast. Distance to the coast was defined as the Euclidean distance from the nearest coastline. The main parametric methods used to analyze the data were simple linear regression, multiple linear regression, and analysis of variance (ANOVA). A model selection approach was used to evaluate different candidate models. For model selection, global models were created for each of the four response variables: log-transformed introduced cover (introduced), log-transformed endemic cover (endemic), native cover (native), and site diversity (diversity) using Simpson's Biodiversity Index:

$$
D^{\prime}=1-\frac{\sum n(n-1)}{N(N-1)}
$$

$D^{\prime}=$ diversity index.

$n=$ number of individuals of each species.

$N=$ total number of individuals.

The global model included six independent variables: "distance to development" (DD), "distance to town" (DT), "distance to coast" (DC), "trail usage" (TU), "elevation" (E), and "canopy cover" (CC). Candidate models were evaluated, and summary statistics were run to determine their significance. Akaike information criterion (AIC) values were then taken for each model where $p<0.05$, and the model with the lowest AIC value was selected as the best fit linear model. For all other models, change in AIC ( $\triangle \mathrm{AIC})$ was calculated by subtracting the AIC of the selected model from the AIC of the other tested models. Akaike weights were also calculated for each model. The Akaike weight informs the probability of each model being the best representative model, with high Akaike weights indicating the model is more likely to be the best model. Only models with an Akaike weight greater than 0.5 are presented in the results. This value is calculated by:

$$
\text { Akaike weight }=\exp \left(-0.05 * \Delta A I C_{\text {model }}\right)
$$

To determine the effect of individual species on diversity, plot diversity was tested against percent cover of three common naturalized species using simple linear regression. The naturalized species used in this analysis were Robinia pseudoacacia, Erigeron annuum, and Sonchus oleraceus. These species were selected because they were present in 10 or more sample plots. For these analyses, only plots where each species was present were used.

In addition to these models, introduced species cover by plot was tested against endemic species cover and plot diversity using simple linear regression to determine what correlation, if any, there was between these two factors and introduced species cover. ANOVA was used to determine whether canopy type influenced understory diversity or composition. Significance was determined at a cut-off of $p<0.05$. Analyses were done in JMP ${ }^{\circ}$ Pro 12.1.0 and RStudio Version 1.0.136.

\section{Results}

\section{Introduced model}

The selected model for the variable "introduced" includes the site factors "elevation," "canopy cover," and "distance to development." A total of nine models were tested along with the global and null models (Table 1). Model 7 (Table 2) had the lowest AIC value and is therefore considered the "best-supported" model, However, model 8 had the next lowest AIC and an Akaike weight of 0.828 , indicating it is $82.8 \%$ likely that model 8 is the best-supported model to explain the data. Models 5 and 6 also have some support with AIC values within 2 of the best-supported model and Akaike weights $>0.5$.

When viewed geospatially (Fig. 3), it is easy to see where the highest concentrations of introduced species are. Particularly, average percent cover is high in areas close to towns in the southeast corner of the island, where the majority of the island's population and tourism occur. Additionally, $87 \%$ of plots containing introduced species occur within $500 \mathrm{~m}$ of development and $100 \%$ of plots containing introduced species occur within $1 \mathrm{~km}$ of development.

\section{Native model}

The selected model for the native variable includes the site factors distance to development and distance to town. A total of six models were tested for this factor, along with the global and null models (Table 3). Model 5 (Table 4) had the lowest AIC value, with model 4 having the second lowest AIC. The Akaike weight of model 4 was 0.879 , indicating it has an $87.9 \%$ chance of being the best-supported model.

\section{Endemic model}

The selected model for the endemic variable includes the site factor trail usage. This variable only had one statistically significant model out of eight models tested (Tables 5 and 6). 
Table 1 Models for introduced species cover

\begin{tabular}{|c|c|c|c|c|c|c|c|c|}
\hline Model & Model ID & Log-likelihood & Number of parameters & AIC & Delta AIC & Akaike weight & $R^{2}$ & $R^{2}$ adj \\
\hline$\overline{T U}, E, C C, D C, D D, D T$ & Global & -86.251 & 7 & 188.502 & 4.374 & 0.112 & 0.215 & 0.158 \\
\hline$T U, E, C C, D C, D D$ & 1 & -86.344 & 6 & 186.688 & 2.560 & 0.278 & 0.213 & 0.166 \\
\hline$E, C C, D C, D D, D T$ & 2 & -86.481 & 6 & 186.962 & 2.834 & 0.242 & 0.211 & 0.164 \\
\hline TU, E, CC, DD, DT & 3 & -86.561 & 6 & 187.122 & 2.994 & 0.224 & 0.209 & 0.162 \\
\hline TU, E, CC, DC, DT & 4 & -87.037 & 6 & 188.074 & 3.946 & 0.139 & 0.201 & 0.153 \\
\hline E, CC, DC, DD & 5 & -86.644 & 5 & 185.288 & 1.160 & 0.560 & 0.208 & 0.171 \\
\hline$T U, E, C C, D D$ & 6 & -86.704 & 5 & 185.408 & 1.280 & 0.527 & 0.207 & 0.170 \\
\hline $\mathrm{E}, \mathrm{CC}, \mathrm{DD} \mathrm{D}^{*}$ & 7 & -87.064 & 4 & 184.128 & 0.000 & 1.000 & 0.200 & 0.173 \\
\hline $\mathrm{E}, \mathrm{CC}$ & 8 & -88.253 & 3 & 184.506 & 0.378 & 0.828 & 0.179 & 0.160 \\
\hline CC & 9 & -92.057 & 2 & 190.113 & 5.985 & 0.050 & 0.107 & 0.096 \\
\hline 1 & Null & -97.129 & 1 & 198.258 & 14.13 & 0.001 & 0.000 & 0.000 \\
\hline
\end{tabular}

TU trail usage, E elevation, CC canopy cover, DC distance to coast, $D D$ distance to development, $D T$ distance to town

* indicates selected model based on Akaike weight

\section{Diversity model}

The selected model for the diversity variable includes the site factors trail usage, elevation, canopy cover, distance to development, and distance to town. A total of nine models were tested for this variable (Table 7). Model 1 (Table 8) had the lowest AIC value, followed by model 2. The Akaike weight of model 2 was 0.844 , indicating it has an $84.4 \%$ chance of being the best model.

\section{Species that impact diversity}

Out of the three common introduced species tested, only Robinia pseudoacacia had a correlation with understory diversity. Where it was present in the understory community, plot diversity decreased with higher percentages of this species (Table 9, Fig. $4 ; R^{2}=0.54, p=$ 0.0246). There was no significant correlation between plot diversity and Erigeron annuum or Sonchus oleraceus percent cover $(p>0.05)$. Other naturalized species encountered in surveys included Amorpha fruticosa, Boehmeria nivea, Chenopodium album, Fallopia dumetorum, Hemerocallis fulva, Houttuynia cordata, Rumex acetosella, Taraxacum officinale, Trifolium repens, and Veronica arvensis. Although these species were not uncommon across the island, they did not occur at high

Table 2 Coefficient table for selected introduced species cover model

\begin{tabular}{lllll}
\hline & Estimate & Std. error & $t$ value & $\operatorname{Pr}(>|t|)$ \\
\hline (Intercept) & 1.3644854 & 0.2079793 & 6.561 & $<0.0001^{*}$ \\
Canopy cover & -0.0092096 & 0.0036963 & -2.492 & $0.0146^{*}$ \\
Elevation & -0.0009022 & 0.0005542 & -1.628 & 0.1072 \\
Distance to development & -0.0003283 & 0.0002163 & -1.517 & 0.1328 \\
\hline
\end{tabular}

Notes: $N=90, R^{2}=0.20, p<0.05$

*Significant at a cut-off of $p<0.05$ enough frequency in the sample plots to be considered for analysis in this study.

\section{Discussion}

Overall, all best-supported models incorporated one or more human-related factors. While their relative influence within each model may be low, this shows that there are implications of human influence on the forest understory aside from habitat destruction due to development. Additionally, introduced species cover correlates with distance to development. It was also found that several species-including an introduced tree species, Robinia pseudoacacia-decreased diversity in plots where they were present. There were no correlations between introduced species and diversity or endemic species, indicating there are no invasive plant species at the time of this study.

\section{Introduced cover}

The model selection results for the introduced variable indicates that canopy cover and elevation are important factors in predicting the percent cover of introduced species: introduced cover declined with more canopy cover and higher elevation. These two variables were included in all the supported models (Table 1). In the best-supported model, introduced cover also declined as the distance to development increased, but this variable was excluded from the next-best model.

In this model, canopy cover has a higher coefficient and a lower $p$ value than elevation, indicating that canopy cover has a greater effect on the introduced cover than elevation. It makes logical sense canopy cover influences introduced species, as many are opportunists and take advantage of greater light availability. It also makes sense for these species to be mostly found in lower elevations because dispersal uphill takes more 


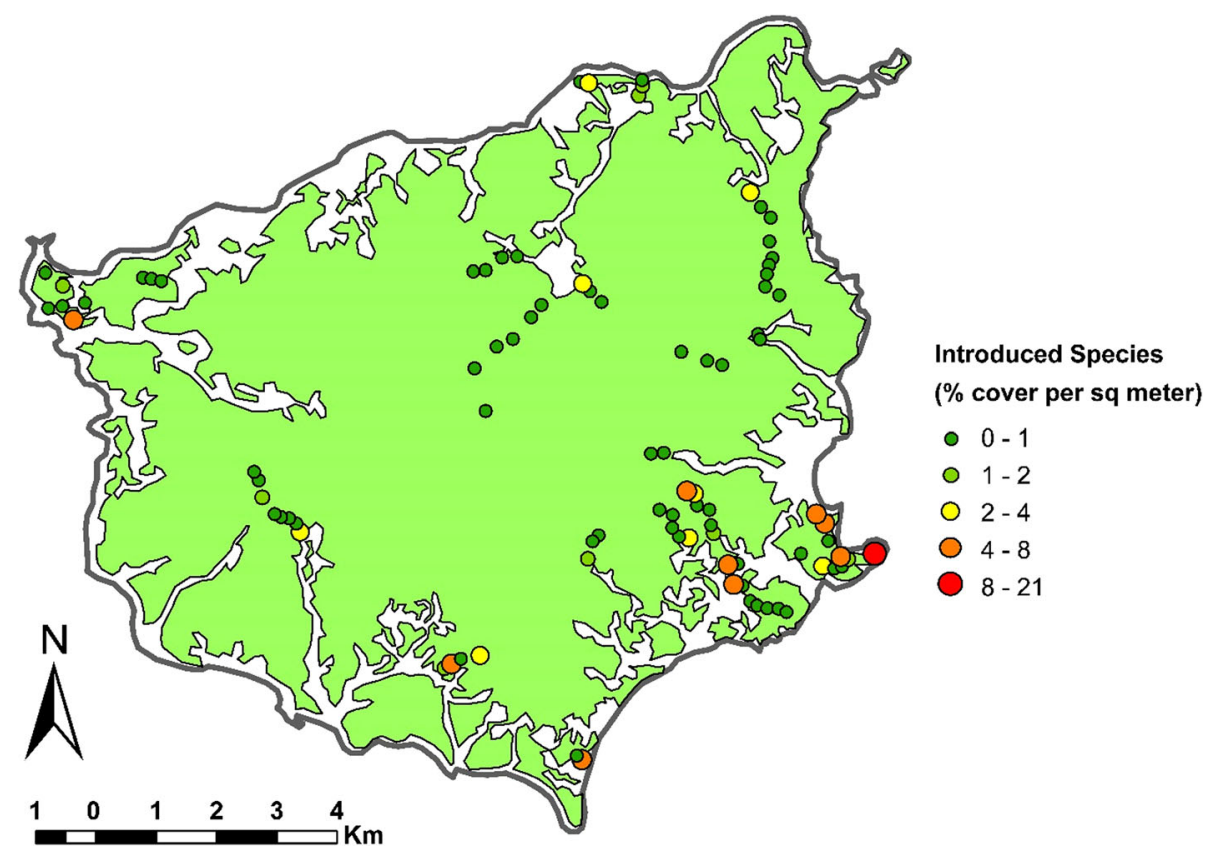

Fig. 3 Introduced species percent cover by survey site

environmental energy than dispersal downhill, and most of the towns on Ulleung Island are in low-lying coastal areas. Dispersal of introduced species to higher elevations would likely require dispersal by animals or humans. Although these introduced species are not very common at higher elevations on Ulleung Island, it should be noted that they are present in small amounts even around Seonginbong-the island's highest peak-likely due to hiking traffic along the trail.

Distance to development, which is also included in the selected model, has the lowest effect on the model. Considering the high Akaike weight of the model that does not incorporate this variable, distance to development does explain as much variation in introduced cover compared to canopy cover and elevation.

The inclusion of distance to development in the introduced model supports the first hypothesis that one of the three human-related site factors is important to predicting introduced species cover.
While the model for the reciprocal of introduced cover only includes a subset of the data and has a low $R^{2}$ value, it does still show a relationship between introduced cover and distance to development that can be readily seen when mapped (Fig. 3). The highest percentages of introduced species will usually be found closer to their sources, which are developed areas where humans have introduced them. Additionally, this model and the lack of significant introduced species cover past $1 \mathrm{~km}$ from distance to development indicate that there are few if any problem areas of introduced species.

\section{Native cover}

Distance to development and distance to town were the two variables that predicted native cover within the selected model. The coefficient of distance to development is positive in this model, meaning that sites farther from developed areas will have a higher percent cover of native species than sites closer to development. This

Table 3 Models for native species cover

\begin{tabular}{|c|c|c|c|c|c|c|c|c|}
\hline Model & Model ID & Log-likelihood & Number of parameters & AIC & Delta AIC & Akaike weight & $R^{2}$ & $R^{2}$ adj \\
\hline$\overline{T U}, \mathrm{E}, \mathrm{CC}, \mathrm{DC}, \mathrm{DD}, \mathrm{DT}$ & Global & -367.827 & 7 & 751.653 & 4.486 & 0.106 & 0.141 & 0.078 \\
\hline $\mathrm{E}, \mathrm{CC}, \mathrm{DC}, \mathrm{DD}, \mathrm{DT}$ & 1 & -367.903 & 6 & 749.806 & 2.639 & 0.267 & 0.139 & 0.088 \\
\hline E, CC, DD, DT & 3 & -368.433 & 5 & 748.867 & 1.700 & 0.427 & 0.129 & 0.088 \\
\hline E, DD, DT & 4 & -368.713 & 4 & 747.425 & 0.258 & 0.879 & 0.123 & 0.093 \\
\hline $\mathrm{DD}, \mathrm{DT} T^{*}$ & 5 & -369.584 & 3 & 747.167 & 0.000 & 1.000 & 0.106 & 0.086 \\
\hline 1 & Null & -374.642 & 1 & 753.283 & 6.116 & 0.047 & 0.000 & 0.000 \\
\hline
\end{tabular}

$T U$ trail usage, E elevation, $C C$ canopy cover, $D C$ distance to coast, $D D$ distance to development, $D T$ distance to town

${ }^{*}$ indicates selected model based on Akaike weight 
Table 4 Coefficient table for selected native species cover model

\begin{tabular}{lllll}
\hline & Estimate & Std. error & $t$ value & $\operatorname{Pr}(>|t|)$ \\
\hline (Intercept) & 72.438843 & 2.888189 & 25.081 & $<0.0001^{*}$ \\
Distance to development & 0.014063 & 0.004591 & 3.063 & $0.00291^{*}$ \\
Distance to town & -0.004956 & 0.002387 & -2.076 & $0.04087^{*}$ \\
\hline $\begin{array}{l}\text { Notes: } N=90, R^{2}=0.11, p<0.05 \\
\text { *Significant at a cut-off of } p<0.05\end{array}$ & & &
\end{tabular}

may be due to an effect of general habitat degradation close to developed areas. Conversely, the coefficient of distance to town is negative, meaning sites closer to towns have higher percent cover than areas farther from towns. This could be due to regional variations across the island, but it has a small coefficient in the model, and therefore a small effect on native species cover. This model also has a low $R^{2}$ value $(0.11)$, which means that it explains a very small portion of the variation within the model.

The significance of both distance to development and distance to town in this model support the first hypothesis that humans indirectly influence native species cover.

The model including elevation had a high Akaike weight $(0.88)$, so it is also possible that elevation influences native cover on Ulleung Island.

\section{Endemic cover}

In predicting endemic cover, only the model including trail usage was significant, meaning that trail usage has the greatest impact on endemic species cover. Since the coefficient in the model is negative, this means that endemic species cover decreases along trails with heavy traffic. However, this model has the lowest $R^{2}$ value (0.05) of the models presented in this thesis, so it is likely that some other untested environmental factor is affecting endemic species cover, or that variation in endemic species cover is due to random chance.

This model supports the first hypothesis that humans influence endemic species cover. Additionally, no other model had a low enough AIC value to be considered.

\section{Diversity}

The selected model for predicting site diversity was the most complex model, including nearly all site factors used in the global model. The one factor not included
Table 6 Coefficient table for selected endemic species cover model

\begin{tabular}{lllll}
\hline & Estimate & Std. error & $t$ value & $\operatorname{Pr}(>|t|)$ \\
\hline (Intercept) & 2.1695 & 0.2380 & 9.116 & $<0.0001^{*}$ \\
Trail usage & -0.2320 & 0.1082 & -2.143 & $0.0349^{*}$ \\
\hline
\end{tabular}

Notes: $N=90, R^{2}=0.05, p<0.05$

*Significant at a cut-off of $p<0.05$

was distance to coast. Some of the site factors are more significant and have more weight within the model, but the inclusion of all but one of the factors in the best fit model indicates that the factors influencing understory biodiversity are complex and varied.

In the diversity model, the most significant site factor with the greatest absolute $t$ value was trail usage. Since the coefficient for this variable is negative, this means that higher trail usage decreases site diversity. This may be due to increased use of forest resources on heavily trafficked trails or to the tendency of trail users on Ulleung Island to leave garbage strewn along the trails. The second most significant site factor is distance to development, which also has a negative coefficient, meaning sites closer to developed areas have slightly higher diversity. This is likely due to the higher number of introduced species, which increases richness and diversity assuming the introduced species themselves are not dominating the plant community and displacing native species.

Next, diversity increases with elevation. Higher elevations are more difficult to get to and alter on Ulleung Island, so they generally have plant communities that most closely represent "untouched" or "natural" communities. They are also more in the temperate region of the island (whereas lower elevations are considered almost subtropical). This may mean less domination of vine species that are common in the lower elevation, more subtropical areas of the island. As the next significant factor, increased canopy cover decreases diversity slightly. More canopy cover means less light availability, which means potentially lower establishment and abundance of certain species. Finally, distance to town is the least significant factor in this model, and has a positive effect on diversity. This is likely due to regional variation or is somewhat unimportant to the model, as the distance to development factor indicates that human activities do in fact influence diversity to a degree.

Table 5 Models for endemic species cover

\begin{tabular}{lllllllll}
\hline Model & Model ID & Log-likelihood & Number of parameters & AIC & Delta AIC & Akaike weight & $R^{2}$ & $R^{2}$ adj \\
\hline TU, E, CC, DC, DD, DT & Global & -111.739 & 7 & 239.479 & 7.553 & 0.023 & 0.075 & 0.008 \\
TU* & 7 & -112.963 & 2 & 231.926 & 0.000 & 1.000 & 0.050 & 0.039 \\
1 & Null & -115.253 & 1 & 234.505 & 2.579 & 0.275 & 0.000 & 0.000 \\
\hline
\end{tabular}

TU trail usage, E elevation, CC canopy cover, DC distance to coast, $D D$ distance to development, $D T$ distance to town

*Only one model was significant at $p<0.05$ 
Table 7 Models for understory diversity

\begin{tabular}{lllllllll}
\hline Model & Model ID & Log-likelihood & Number of parameters & AIC & Delta AIC & Akaike weight & $R^{2}$ & $R^{2}$ adj \\
\hline TU, E, CC, DC, DD, DT & Global & 85.306 & 7 & -154.611 & 1.262 & 0.532 & 0.260 & 0.207 \\
TU, E, CC, DD, DT* & 1 & 84.919 & 6 & -155.873 & 0.000 & 1.000 & 0.254 & 0.209 \\
TU, CC, DC, DD, DT & 2 & 84.767 & 6 & -155.534 & 0.339 & 0.844 & 0.251 & 0.207 \\
TU, CC, DD, DT & 3 & 82.641 & 5 & -153.282 & 2.591 & 0.274 & 0.215 & 0.178 \\
TU, CC, DD & 4 & 78.243 & 4 & -146.486 & 9.387 & 0.009 & 0.134 & 0.104 \\
TU, DD & 5 & 77.694 & 3 & -147.388 & 8.485 & 0.014 & 0.124 & 0.103 \\
TU, CC & 6 & 78.228 & 3 & -148.456 & 7.417 & 0.025 & 0.134 & 0.114 \\
TU & 8 & 77.620 & 2 & -149.240 & 6.633 & 0.036 & 0.122 & 0.112 \\
1 & Null & 71.759 & 1 & -139.518 & 16.36 & 0.000 & 0.000 & 0.000 \\
\hline
\end{tabular}

$T U$ trail usage, E elevation, CC canopy cover, $D C$ distance to coast, $D D$, distance to development, $D T$ distance to town

* indicates selected model based on Akaike weight

The model for site diversity supports the first hypothesis that human activities indirectly influence diversity.

\section{Species that impact diversity}

When individual species were compared with biodiversity within individual plots, it became apparent that ubiquitous native species had a greater influence on diversity than did the three most common introduced species. The decrease in biodiversity for plots with the native species likely had to do with the dense root formations of all of these species, with high percent cover leading to crowding out roots of other species.

The decrease in diversity in plots where Robinia pseudoacacia is present may be due to environmental variables affecting the success of $R$. pseudoacacia or to R. pseudoacacia altering its environment. However, it is still important to note that only 9 plots out of 270 are represented by this result, and therefore any impact of $R$. pseudoacaia abundance is currently not very great for ecosystems across the island. For the two other introduced species, it is likely that their abundance is so insignificant that those species do not affect the dynamics of the surrounding plant communities.

Table 8 Coefficient table for selected understory diversity model

\begin{tabular}{lllll}
\hline & Estimate & Std. error & $t$ value & $\operatorname{Pr}(>|t|)$ \\
\hline (Intercept) & 0.7777 & 0.04604 & 16.892 & $<0.0001^{*}$ \\
Trail usage & -0.03568 & 0.01401 & -2.547 & $0.0127^{*}$ \\
Elevation & 0.0001941 & 0.00009 & 2.088 & $0.0398^{*}$ \\
Canopy cover & -0.001160 & 0.00057 & -2.034 & $0.0451^{*}$ \\
Distance to development & -0.000077 & 0.00004 & -2.133 & $0.0358^{*}$ \\
Distance to town & 0.0000338 & 0.00002 & 1.823 & 0.0719 \\
\hline
\end{tabular}

Notes: $N=90, R^{2}=0.25, p=0.0349$

*Significant at a cut-off of $p<0.05$

\section{Conclusions}

Implications of models on Ulleung Island understory plant communities

The models selected to best represent the vegetation data collected on Ulleung Island indicate that human activities have slight impacts on the understory plant communities of the island. First, human activities somewhat increase the percent cover of introduced species closer to developed areas. Humans likely have little control over spreading of introduced species, with the exception of escaped cultivated species like Boehmeria nivea, and introduced species do not appear to negatively impact the native plant communities of the island. This is especially apparent in the lack of influence secondary human activities have on native and endemic species percent cover. Secondary activities in this case primarily include the introduction of native species and general degradation that happens with human proximity and use of forested areas.

Although these secondary human activities on Ulleung Island do not impact native and endemic groupings, it is somewhat concerning that understory diversity decreases with increased trail usage. While this may be due to overgrowing along trails that are not kept up, it may indicate poor environmental stewardship of trail users. This could be because of a lack of awareness of ecological and environmental processes. Anecdotally, Koreans tend to be very culturally invested in their forests, but environmental science and ecology are often less important to them. This is apparent in the abundance of trash that is sometimes

Table 9 Coefficient table for biodiversity $\left(D^{\prime}\right)$ by Robinia pseudoacacia

\begin{tabular}{lllll}
\hline & Estimate & Std. error & $t$ value & $\operatorname{Pr}(>|t|)$ \\
\hline (Intercept) & 0.8864827 & 0.029999 & 29.55 & $<0.0001^{*}$ \\
Robinia pseudoacacia & -0.008891 & 0.003116 & -2.85 & $0.0246^{*}$ \\
\hline
\end{tabular}

Notes: $N=9, R^{2}=0.54, p<0.05$

*Significant at a cut-off of $p<0.05$ 


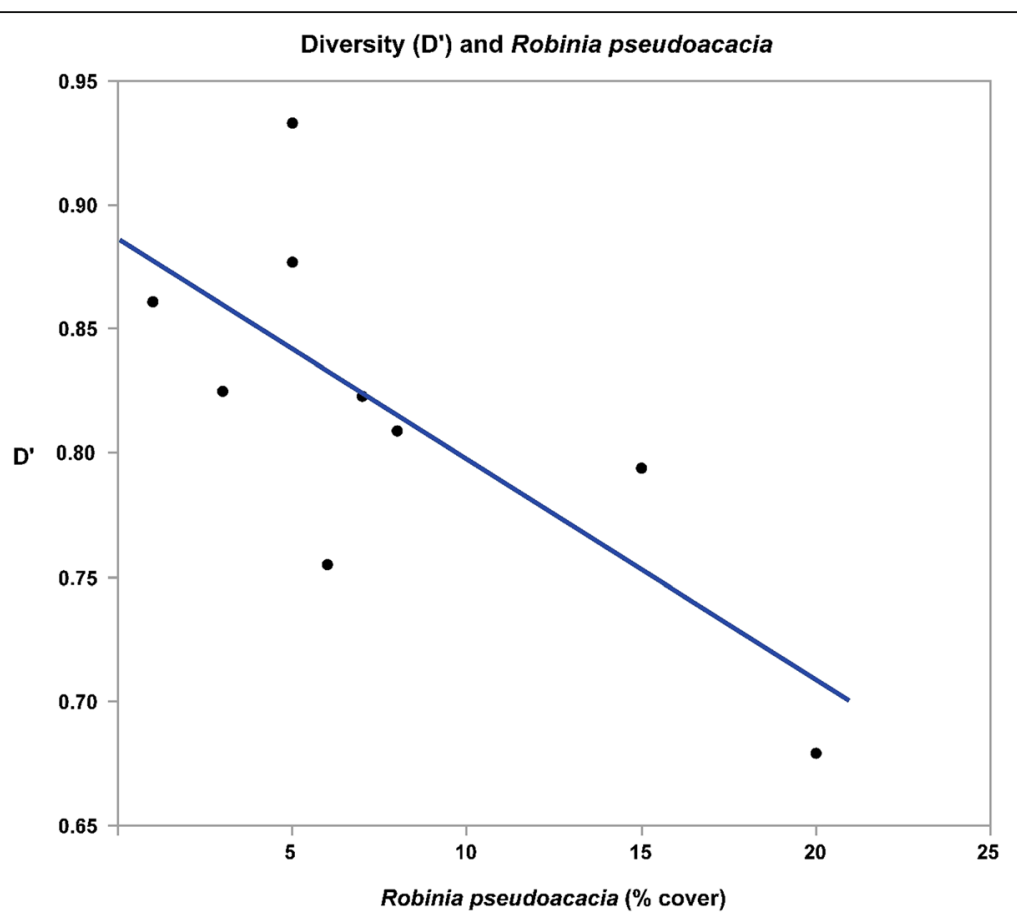

Fig. 4 Understory diversity by Robinia pseudoacacia

present along the more popular trails on the island. Degradation along popular trails may be exacerbated by the large amounts of tourists the island sees every year.

\section{Implications for analogous islands}

Secondary influences caused by human activities likely do not significantly impact understory plant communities on other temperate islands. While the story may be different on tropical islands or unforested islands, the forest cover, climate, and potentially limited resources on temperate islands make establishment and invasion difficult for exotic plant species. Further, the limited impacts of these exotic species on the native and endemic species of Ulleung Island indicate that there may be little impact on analogous islands.

The exceptions would be islands where one or two particularly invasive species are introduced and spread, or where a non-invasive introduced species displaces a rare endemic species. The latter would be difficult to detect in studies of the whole plant community, and a targeted survey for the at-risk species would have to occur to determine decline and displacement by exotic species. In this case, a time series study of percent cover of introduced species and community ordination in areas where the target species occurs would be appropriate.

To further determine the secondary effects of human landscape development on the understory vegetation communities of Ulleung Island and analogous temperate islands, baseline studies-like the one presented in this thesis-and continued monitoring of these communities is necessary. However, it is likely that declines in richness and diversity are caused by habitat destruction and are, at best, only minimally influenced by secondary human activities.

\section{Suggestions for future study}

Opportunities to build on this study are plentiful, and future study would add to the understanding of human effects, vegetation communities, and effects of climate change. This study can be expanded on Ulleung Island to include more study sites, species, and time series. This study can also be replicated on analogous islands.

In future studies, it would be beneficial to add more study sites to cover more of the island or to establish permanent study sites for continued monitoring. First, sites above $600 \mathrm{~m}$ can be added to expand understanding of plant communities. Second, more remote areas could be accessed over time to include areas that are relatively untouched by human disturbance. Further study may also include gathering more environmental data and quantifying human use of trails and forest resources across the island. Monitoring should occur periodically to determine the effects of increased tourism and climate change on the island. Warming could push endemic species to higher elevations, eventually removing their habitable area from the island entirely. One example of this is the endemic species Corydalis filistipes, which is 
already very rare and is primarily found in the highest elevations of the island (Andersen, 2015).

\section{Suggestions for conservation}

The results of this study can inform future conservation efforts for Ulleung Island and analogous islands. Future efforts, on Ulleung Island specifically, should focus on environmental awareness and on reducing complete habitat destruction.

Because plant groups and communities are affected only slightly or not at all by the secondary impacts of human activities, there is little need for costly restoration of existing ecosystems. Instead of spending funds on eradicating exotic invasive species, funds can be spent on reducing the amount of new exotic species introduced. Additional funds can be spent improving education and signage along trails on the island. Currently, there are some signs showing forest succession and the importance of primary forest, as well as signs about ecological processes and endemic species on the island, but there is much to be desired in terms of conservation and reducing the impact of visitors to the island.

Further understanding of the importance of the island's ecosystems and species can also contribute to the designation of ecologically important areas. This study, along with other ecological studies and a number of genetic studies, help solidify the ecological value of the island. A large portion of the island's forest is designated as a Forest Genetic Resources Reserve (FGRR) by the South Korean government (Korea Forest Service, 2007), and there are many "natural monuments" designated on the island, but more and stronger designations could help reduce habitat destruction for development. Even in the 3 years between the author's initial and data collection visits, there has been significant environmental destruction from development, as interest in Ulleung and Dokdo Islands has increased tourism to both islands. Reducing development by increasing environmental protection will be the most effective way to preserve diversity on Ulleung Island and its species that are at the highest risk of extinction.

\section{Abbreviations}

AIC: Akaike information criterion; CC: Canopy cover; DC: Distance to coast DD: Distance to development; DT: Distance to town; E: Elevation; TU: Trail usage

\section{Acknowledgements}

Thank you to Professor Dylan Fischer of The Evergreen State College for advising during data collection and analysis. Thank you to Professor John Withey of the Evergreen State College for advising during analysis and revision. Thank you to Professor Seung-chul Kim of Sungkyunkwan University for hosting during data collection in Korea.

\section{Funding}

This work was supported by the National Science Foundation of the United States under Grant \#1613885.
Availability of data and materials

Raw data available at https://www.dropbox.com/s/22iyijtm9dmsh2i/ Statistics_Workbook.x|sx?d|=0

\section{Author's contributions}

DA conducted all project conception, literature review, field data collection, data analysis, and manuscript writing. Advisors contributing help with analysis and manuscript review declined co-authorship. The author read and approved the final manuscript.

Ethics approval and consent to participate Not applicable.

\section{Consent for publication}

Not applicable.

\section{Competing interests}

The author does not declare any conflict of interest. This manuscript has not been published or submitted for publication elsewhere. The materials supporting the manuscript do not overlap with any other articles published or in press. All persons entitled to authorship have been named.

\section{Publisher's Note}

Springer Nature remains neutral with regard to jurisdictional claims in published maps and institutional affiliations.

Received: 17 March 2019 Accepted: 22 April 2019

Published online: 14 May 2019

\section{References}

Adsersen H. Research on islands: classic, recent, and prospective approaches. Islands: Springer; 1995. p. 7-21.

Andersen D. Natural history guide to Ulleungdo: South Korea's mysterious island. USA: CreateSpace Independent Publishing Platform; 2015.

Eliasson U. Patterns of diversity in island plants. Islands: Springer; 1995. p. 35-50. Heywood VH. The future of island floras. Plants and Islands. 1979;1:431-41.

Jung S-Y, Park S-H, Nam C-H, Lee H-J, Lee Y-M, Chang K-S. The distribution of vascular plants in Ulleungdo and nearby island regions (Gwaneumdo, Jukdo), Korea. Journal of Asia-Pacific Biodiversity. 2013;6(1):123-56.

Korea Forest Service. (2007). Research for Conservation and Management Plan of Genetic Resources Reserve.

Nakai T. Report on the vegetation of the island Ooryongto or Dagelet Island, Corea, February, 1818 [i.e. 1918]. Seoul: Pub. by the government of Chosen; 1919.

Oh S-Y. Floral studies on the vascular plants of the Dagelet Island. Taegu: S.n; 1978

Sax DF, Gaines SD. Species invasions and extinction: the future of native biodiversity on islands. Proc Natl Acad Sci U S A. 2008;105:11490-7.

Vitousek PM. Diversity and biological invasions of oceanic islands. Biodiversity. 1988:181-9.

Vitousek PM, Loope L, Adsersen H. Islands: biological diversity and ecosystem function. New York: Springer-Verlag; 1995.

Yang S, Jang H-D, Nam BM, Chung GY, Lee R-Y, Lee J-H, Oh B-U. A florisitic study of Ulleungdo Island in Korea. Korean Journal of Plant Taxonomy. 2015:45(2):192-212.

Yoon JW, Shin HT, Yi MH. Distribution of vascular plants in the Ulleung Forest Trail area, Korea. Journal of Asia-Pacific Biodiversity. 2013;6(1):1-30.

Ready to submit your research? Choose BMC and benefit from:

- fast, convenient online submission

- thorough peer review by experienced researchers in your field

- rapid publication on acceptance

- support for research data, including large and complex data types

- gold Open Access which fosters wider collaboration and increased citations

- maximum visibility for your research: over 100M website views per year

At BMC, research is always in progress.

Learn more biomedcentral.com/submission 